\title{
Pedestrian Bridge Application in a Fundamentals of Structural Analysis Course Inside an Architecture Bachelor Program
}

\author{
https://doi.org/10.3991/ijep.v11i5.20151 \\ Maria Giulia Ballatore ${ }^{1(\varpi)}$, Fabrizio Barpi ${ }^{1}$, Dan Crocker $^{2}$, Anita Tabacco $^{1}$ \\ ${ }^{1}$ Politecnico di Torino, Torino, Italy \\ ${ }^{2}$ DC Structures Studio, Cambridge, New Zeland \\ maria.ballatoredpolito.it
}

\begin{abstract}
The paper presents an application of the Problem-Based Learning (PBL) methodology in a structural analysis course taught in English of the third year Architecture bachelor program at Politecnico di Torino (Italy). This experimentation regards a class composed mainly of international students. That is a heterogeneous audience with different backgrounds. In general, students struggle with the technical aspects typical of the structural analysis course. PBL has been found as a possible solution to this problem in Engineering programs. The aim of redesigning the course is to support students' learning while evaluating the PBL application in a non-technical context with an international audience. This article describes the structure and the results of the PBL implementation. In particular, the participation has increased compared to the previous academic year in terms of presence during the lectures, interest in the subject, the interaction between the lecturer and the students, and exams' results. These results are encouraging and confirm the validity of the PBL methodology as actually applied.
\end{abstract}

Keywords—structural analysis, PBL, architecture bachelor program, pedestrian bridge

\section{Introduction}

Fundamentals of Structural Analysis (FSA) is a third-year mandatory course of the Architecture bachelor program at the Politecnico di Torino. This bachelor's degree has two different tracks: one taught in Italian, with around 450 students (divided into three parallel groups), and one in English, with almost 75 students. In the Italian path, students are mostly coming from Italy. On the contrary, in the English one, there is an international audience with students coming from different countries, in particular from Asia and South America.

Due to its nature, the FSA course has high technical and engineering content. Usually, architecture students struggle in understanding both the theoretical aspects and the manual and numerical solution procedures. One of the aspects that non-technical students typically find hard is the shift from the theoretical concepts to the qualitative evaluation that this topic requires. This shift is unusual for students in general, but even 
more for the architectural ones that in their study are not comfortable with this approach. This difficulty is even more evident in the English track, in which students' backgrounds are very heterogeneous since they came from different nations with a variety of school systems. Although the courses in the first two years already tried to fill the preexisting educational gap.

In the past years, the methodology used in this course has been following a traditional face-to-face teaching model with a single lecturer supported by slides with some exercises on the blackboard. In the meantime, at the end of the course, only a few students succeeded in passing it. For example, in the academic year 2018/19 of the 55 enrolled, only five were successful at the final exam in the winter call (first call available). Moreover, the student's level of engagement during the course has been critical in terms of presence during the lectures and interaction with the lecturer.

Data from several studies suggest PBL (Problem-Based-Learning) methodology as an excellent solution to approach the learning difficulties typical of a structural analysis content inside technical schools $[1,2,3,4,5]$. In general, PBL is applied in many engineering courses as it seems to suit the professional requirement of a mix of technical and practical competencies $[6,7,8,9]$. Using this methodology in a non-technical context, such as an Architecture bachelor degree, is not trivial and requires some shrewdness [10]. The present research explores the effects of this methodology in an Architecture bachelor degree with an international audience, such as the English curricula.

The main objectives to redesign the course were the overall subject framework, the themes and types of problems, and the proposal for PBL work. To do this, the Chandrasekaran and Al-Ameri study [6], together with the Bridges' critical review [10], played a fundamental role. The first one investigated the engineering students' experience in team learning practice and in particular in project/design-based learning and found out that $[6]$ :

- Students prefer to have a balance between lecture and design class, with a possible unbalance in favour of design class

- The assessment should equally include the project and a formal individual exam. In general, engineers prefer to be assessed individually rather than through teamwork

- Group size should be between three and five students distributed based on their own preference

- A group leader is perceived as fundamental, although the self-estimation of participation can vary among members.

Said this, the non-technical environment typical of Architecture education has some different features compared to the Engineering one. Therefore, the lecturer must work with educational specialists and decision-makers to design an architectural version of PBL [10]. Bridges has also underlined some focal points that we used as a guideline in the designing stage:

- the complexity of the problem: it should be enough complex and actual to attract students but simple to be affordable with their knowledge

- open-endedness of the problem: it should favour a brainstorming activity fostering the team to evaluate different solutions 
Paper-Pedestrian Bridge Application in a Fundamentals of Structural Analysis Course Inside an...

- duration of assessment: students should have time to be meaningfully engaged with the problem

- degree of collaboration amongst students: the design should support students' interaction inside the team

- explicit incorporation of reflection: reflection on learning outcomes support the learning itself. Students need to become confident with the new skills and awareness of the personal learning achievement

- variety of skills required: the project solution should develop different skills by requiring different project presentation formats (i.e., images, reports, oral presentations, elevator speeches)

- diversity of media: the solution can require the use of various media, for example, hand vs software calculation or traditional manual drawing vs CAD modelling

- use of precedents: students should have access to sufficiently detailed and accurate sources of material to work with

- collaborative development of problem definition: joint participation of students in the problem definition will make the project more effective.

Moreover, referring to the typical theoretical learning principles that De Graaff and Kolmos identified [11], the course framework has been defined as reported in Table 1.

Table 1. Course design based on the typical theoretical PBL learning principles (the first column refers to [11])

\begin{tabular}{|c|c|}
\hline $\begin{array}{l}\text { Typical PBL theoretical learning } \\
\text { principles }\end{array}$ & FSA redesign framework \\
\hline $\begin{array}{l}\text { Problem-based learning: the problems are based on } \\
\text { real-life issues which have been selected and edited to } \\
\text { meet educational objectives and criteria }\end{array}$ & $\begin{array}{l}\text { The chosen problem is the design of a pedestrian } \\
\text { bridge and its structural analysis. }\end{array}$ \\
\hline $\begin{array}{l}\text { Participant-directed learning processes: students have } \\
\text { the opportunity to determine their own problem for- } \\
\text { mulation within the given subject area guidelines }\end{array}$ & $\begin{array}{l}\text { The teacher will provide the students with a de- } \\
\text { tailed guideline to support the problem approach } \\
\text { and help them identify a feasible solution. }\end{array}$ \\
\hline $\begin{array}{l}\text { Experience learning: to link the formulation of the } \\
\text { problem to the individual's world of experience in- } \\
\text { creases motivation }\end{array}$ & $\begin{array}{l}\text { Each team of students can choose the location, the } \\
\text { shape, and the material to be used for the bridge de- } \\
\text { sign }\end{array}$ \\
\hline $\begin{array}{l}\text { Activity-based learning: requiring activities involving } \\
\text { research, decision-making and writing }\end{array}$ & $\begin{array}{l}\text { Students will need to submit reports periodically. } \\
\text { Moreover, in the initial design stages, they will } \\
\text { need to make decisions based on personal research; } \\
\text { while in the structural analysis, they will need to } \\
\text { review the results obtained and make proper } \\
\text { changes critically }\end{array}$ \\
\hline $\begin{array}{l}\text { Inter-disciplinary learning: teachers do not just con- } \\
\text { sider objectives within the known subject-oriented } \\
\text { framework but also consider problems or real situa- } \\
\text { tions }\end{array}$ & $\begin{array}{l}\text { To solve the pedestrian bridge problem, students } \\
\text { need to consider the mechanical properties of mate- } \\
\text { rials, the esthetical aspects, and the environmental } \\
\text { constraints that they have learnt in previous courses }\end{array}$ \\
\hline $\begin{array}{l}\text { Exemplary practice: The students must acquire the } \\
\text { ability to transfer knowledge, theory, and methods } \\
\text { from previously learned areas to new ones }\end{array}$ & $\begin{array}{l}\text { The teacher will foster the ability to generalize the } \\
\text { learning knowledge }\end{array}$ \\
\hline $\begin{array}{l}\text { Group-based learning: whereby the majority of the } \\
\text { learning process takes place in groups or teams }\end{array}$ & The students will work in teams of 3-4 people each \\
\hline
\end{tabular}


Paper-Pedestrian Bridge Application in a Fundamentals of Structural Analysis Course Inside an...

This paper highlights the general results obtained by implementing the PBL methodology in an FSA course starting from the work in progress outputs presented at the EDUCON 2020 Conference [12]. Section 2 provides a general description of the context and states the research questions. Section 3 describes the methodology used and the course implementation, Section 4 analyzes the results obtained, and Section 5 draws conclusions and discusses future developments.

\section{Background}

In the international context, the difficulties typical of the structural analysis have been addressed with a PBL implementation $[1,2,3,4,5]$. While solving the problem, students learn how to carry out the calculation and how to address metacognition. In qualitative analysis research, which measures the impact of the PBL in this topic, Justo et al. highlight the main strengths: teamwork, self-directed learning, continual assessment, practical approach, and faculty involvement. Although, in the meantime, the study identifies some drawback points such as the disorientation experienced by the students at the beginning and the different degree of involvement and workload of team members. These findings suggest the importance of tutorship in approaching the project and on the orientation and evaluation of equal task distribution inside the team [3].

Moreover, tutoring activities have been identified as key for improving the conceptual understanding of students. However, a significant improvement in the comprehension of bending moment distribution seems to be hard to reach with only the tutors' support [4]. Moreover, the lecturer needs to guide the shift in the learning techniques [13].

Then, another essential aspect becomes the integration of the project into the course topics. Morgan and Barroso suggest creating an explicit tie between the project tasks, outcome and the course contents. Establishing this clear link helps the students understand that the project itself is a way to put together the different concepts personally [5].

Considering the assessment side, it must fit the objectives of the learning process. That is, to verify the competence acquired rather than a limited test on individuals' knowledge [11].

\subsection{Course context and purpose}

At Politecnico di Torino, FSA is taught in the traditional face-to-face way: the teacher at the blackboard with slides or chalk, and students take notes. It lasts one semester, from October to January, and, as for other courses, the assessment is limited to a multiple-choice test to evaluate the students' knowledge. Students have four available dates to do the final exam: two right after the end of the course (one in January and one in February), one after the second semester (in July) and one after the summer period (in September).

The technical content and methodology used during the lessons make it hard for architecture students to approach the subject's study properly. It is important to remark 
that FSA is an introductory course. Therefore, the following Structural Engineering courses during the Master degree will cover a comprehensive discussion about the appropriate technical standards, load combinations, elastoplastic design, seismic actions, structural details. Although the basic nature of the course, students are asked to familiarize themselves with Nòlian, an Italian FEM analysis application [14]. This tool is frequently used by Italian professionals but is not available in English, and this represents a partial problem for the international audience of this course.

This approach highlighted a few problems and limitations: lack of interaction with the students, poor results at the final evaluation that seems to show a poor understanding of the topics and a long time passing the exam.

These aspects are more evident in the English track, where there are also differences in students' background knowledge. Students are coming from worldwide and may have different experiences and expertise, although sometimes they don't have sufficient math preparation. We analyze their results in the academic year 2018/19: only $11 \%$ succeed in the exam at the end of the course during the winter session, $73 \%$ pass the exam during the other sessions, and $16 \%$ did not succeed in any sessions.

\subsection{Objectives of the study}

This study will analyze two different relationships with the PBL:

- How can the PBL favour the learning of a technical subject in an Architecture program?

- How can the PBL favour the learning of a class composed of international students with a heterogeneous background?

Different qualitative aspects are collected and analyzed, thanks to direct observation, structured project revision, presentations and final survey to answer those questions.

\section{Redesign implementation and methodology}

This new course design aims to support students' learning, particularly considering the technical aspects key for the structural analysis. This change will apply only to the English track that seems more penalized by the traditional approach. In order to implement the PBL methodology, the entire course organization needed to be reviewed. First of all, the project that the students need to develop has to be defined considering the traditional content of the course.

For this reason, it needs to have the characteristics of a preliminary study with simple calculations. In the meantime, although the goal of the course is not to do a complete standard-compliant design, the project needs to consider the national regulation to help the students understand the complexity of real-life structural analysis. A small/medium size footbridge (about $15 \mathrm{~m}$ to $20 \mathrm{~m}$ ) has been chosen as a project theme following these characteristics. This theme is simple enough to be examined with the tools provided during the lessons, and it can be partially solved manually and/or by using structural software, like Nòlian. 
The reference project has been identified in the pedestrian bridge developed by the DC Structures Studio of Cambridge (NZ) [15], which introduce the project by saying:

If you find these designs useful or have any improvements, please leave us a comment. Our team is driven by a passion for bridge design (we love bridges!). Hence, we are very proud of this set and hope to see it used throughout NZ. We would really appreciate hearing any feedback you might have: Is this standard bridge useful? What changes would make it better? Would you consider using it? What updates or additions would you like to see?

Thanks to the interaction with the DC designers, the whole project was made available for the course (Fig. 1 shows an example) [15], together with other sources of inspirations $[16,17,18,19]$. Students can design and imagine possible variations to improve this original project's architectural and structural aspects or create a new one with similar characteristics. Moreover, considering the international audience, each team of students can locate the bridge somewhere in Italy or their country of origin and choose as building material one typical of their region. However, to define the material properties, each team must be coherent with the country selected and, therefore, needs to consider the building regulation that varies country by country. If the national regulation is not readily available, the lecturers with the tutors can decide to use the Italian and EU regulation as a reference $[20,21]$. In general, the project needs to follow the KISS principle, that is, Keep It Simple Stupid [22].

\section{NZ PEDESTRIAN FOOTBRIDGE WITH HORIZONTAL WIRE BALUSTRADE}

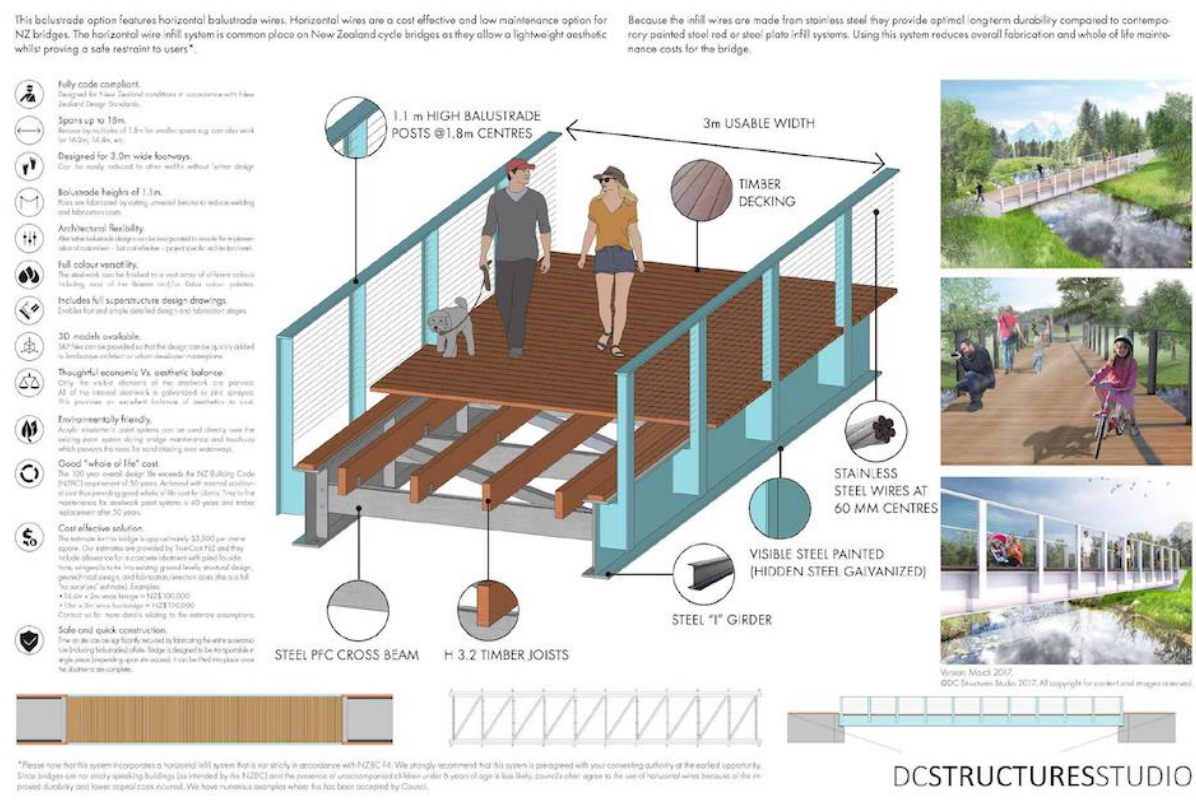

Fig. 1. New Zealand standard footbridge design (elementary $18 \mathrm{~m}$ pedestrian bridge). 
Considering the course content, the critical technical aspects of the project have been identified and adequately included in the course material. In particular, the course will be divided into

- theoretical lessons (30\%): lecturer guides the students into the project contents

- teamwork (30\%): each group apply the theoretical concepts to the bridge design

- tutoring activities (30\%): each group can meet a tutor to share doubts and ideas

- presentations (10\%): time in which each group present a specific step of the bridge design.

The theoretical lessons follow a traditional approach; the lecturer uses both slides and a blackboard. The content has been reorganized, neglecting the more general parts of elasticity and continuum mechanics and stressing the contents strictly related to the project (i.e., with new comments, exercises, data and suggestions). Moreover, for the topics related to the project, a yellow background in the slides has been used to help the students easily recognize it.

The students have three times a week a formal activity following the calendar shown in Table 2.

Table 2. Calendar of the activity divided by week

\begin{tabular}{|l|c|c|c|}
\hline Week number & Lesson 1 & Lesson 2 & Lesson 3 \\
\hline 1 & Lecture & Project description and team formation & Lecture \\
\hline 2 & Lecture & Tutoring & Lecture \\
\hline 3 & Lecture & Team 1st presentation & Lecture \\
\hline 4 & Lecture & Tutoring & Lecture \\
\hline 5 & Lecture & Tutoring & Lecture \\
\hline 6 & Lecture & Team 2nd presentation & Lecture \\
\hline 7 & Lecture & Tutoring & Lecture \\
\hline 8 & Lecture & Tutoring & Lecture \\
\hline 9 & Lecture & Tutoring & Lecture \\
\hline 10 & Lecture & Team 3rd presentation & Lecture \\
\hline 11 & Lecture & Tutoring & Lecture \\
\hline 12 & Lecture & Tutoring & Lecture \\
\hline 13 & Lecture & Tutoring & Lecture \\
\hline 14 & Tutoring & Final presentation & Final presentation \\
\hline
\end{tabular}

At the end of the course, during the final presentation, the best projects and related reports will be voted by a committee of academic lecturers and experts in the field. Then, the studio's website will publish the best ideas.

As part of the redesign, also the assessment has been modified. The Italian education system foresees a final exam for each course evaluated over a scale of 30 . The exam is considered positive with a score of 18/30. In particular, the final exam is composed of a multiple answers test (18 points) and the bridge design (12 points). The project evaluation includes the observations and the votes done by the committee during the final 
Paper-Pedestrian Bridge Application in a Fundamentals of Structural Analysis Course Inside an...

presentation. For those students who did not deliver any final project, the assessment remains like in the previous academic year: a 30 questions multiple answers quizzes.

\subsection{Methodology}

This paper presents a qualitative analysis of a study case that includes only the English track, which, in the academic year 2019/20, is composed of 62 students. Only 4 of them coming from Italy, while the others are mainly from Asia and South America.

Each team has a maximum of 4 people to ensure good and homogeneous cooperation between them. The team size is crucial to enriching soft skills such as teamwork, communications, organization, and leadership.

As said in the redesign, the new course will be structured in theoretical lessons (30\%), teamwork (30\%), tutoring activities $(30 \%)$, and presentations $(10 \%)$. The teamwork is autonomously organized and is not included in the official course schedule.

The tutoring sections consist of 15 minutes sessions in which every team can personally discuss its project with one tutor. The tutors are civil engineer master students selected through a call, available for a maximum of 60 hours each during the entire course. For the academic year 2019/20, three tutors have been assigned to the FSA course, which guarantees a strong interaction in terms of time with the teams. In the past, tutoring sessions were also available on a reservation basis to help the theoretical understanding.

The presentations are four, distributed over the entire semester. During each of them, each team is required to explain the progress of the design. The first three presentations last 3 minutes each. Instead, the final presentation lasts 10 minutes and will be in a video conference with DC Structures Studio. Overall, students are expected to deliver a well-structured, one-page report in the first three presentations and a complete project report with all the design details in the final one.

During the first lesson, the new course design has been explained to the class with a deep look into the project requirements. This includes the instructions regarding the content that each team needs to present inside the 3 minutes speech:

$-1^{\text {st }}$ presentation: students should explain a basic structural scheme, materials, load, design and location of the bridge

$-2^{\text {nd }}$ presentation: students should present the deformability and stability

$-3^{\text {rd }}$ presentation: students need to show the strength, horizontal loads and bracing effect, and the 3D numerical model.

While for the final 10 minutes presentation, each team must present the whole project.

Regarding the project characteristics, the building regulation chosen as a reference needs to be used for the loads' calculation, including dead load, live load, self-weight, snow, a horizontal force on the balustrade. At the same time, wind and earthquake loads are neglected. The structure calculation entails being partially solved manually by using equilibrium equations for which the structure should be statically determined. Only after this manual approach, the structure is solved using the structural software Nòlian. 
In this stage, students should evaluate the numerical results comparing the analytical solution in terms of stress (strength), displacements (stiffness), instability (stability) and the numerical solution. Moreover, they need to discuss horizontal bracing by applying horizontal forces (10\% to $15 \%$ of the vertical forces). If the team chooses an Italian area, the national regulation is already present inside the FEM software; otherwise, it must consider the national restrictions manually.

For the final report (about 5-10 pages long), a detailed guideline is made available to students and covers the following points:

- summary (description of the problem)

- introduction (overview and main issues)

- problem description (assumptions, drawings, solution procedures, theory assumptions)

- results (presentation, explanation, supporting theory, numerical results, implications)

- conclusions and recommendations

- references (technical standards, other helpful material)

- appendices.

Moreover, some insight references have been given to support further the students' writing process $[23,24]$.

Looking at the assessment, the evaluation includes a test and the project work. The test is made of 18 items, 12 theoretical and 6 related to the software application. It is considered passed if $12 / 18$ are answered correctly, independently on the type of questions. Regarding the project evaluation, in addition to the final presentation, the entire evolution of the solution will be considered (the three minutes presentations, the material delivered, and the tutoring sections).

We used different qualitative approaches to analyze the implementation of the redesigned course:

- observation of the course flow done by a researcher unfamiliar with the course topic that considers the methodological approach and the class responses and by a technical expert that looks at the contents

- team revision's sheets (Fig. 2) filled by the tutors during the tutoring activities

- presentations' material that each team delivers during the course (reports and final presentation)

- course survey evaluations that students anonymously return at the end of the course. 


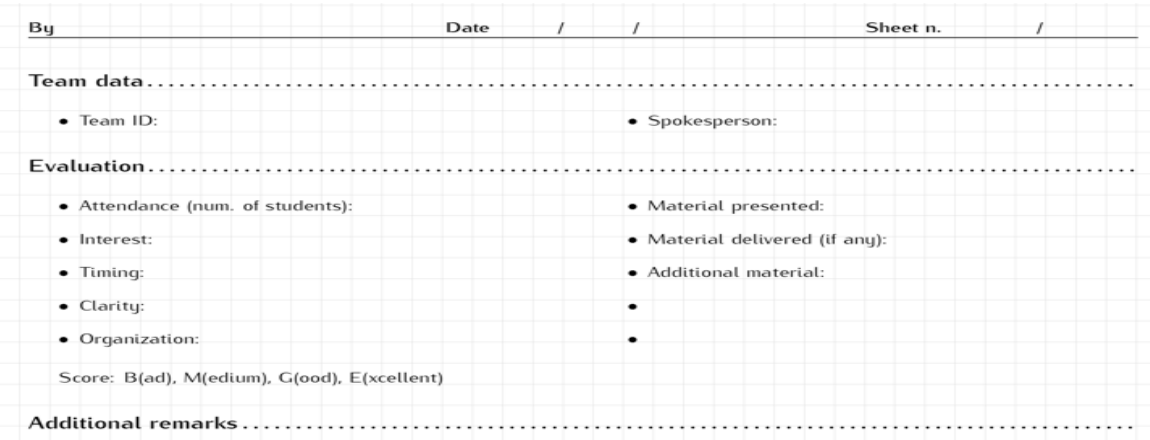

Fig. 2. The form that the tutor needs to fill after each team revision.

The team revision's sheets should be weekly and include both general skills and technical aspects. For example, by looking at them, one can suppose the workload distribution inside the team (general skills) and the ability to correct mistakes and include the tutor's suggestions (technical aspects).

The central administration manages the anonymous student survey delivery and evaluation for all courses. Students can fulfill it starting from the last weeks of the course until the first exam session starts. It is not mandatory, but students are highly encouraged to complete them. Six modules make it with Likert-scale answers [no, more no than yes, more yes than no, yes]:

- Attendance (Question 0): Students must indicate the attendance rate. The general statistics considers only students with $>50 \%$ of frequency

- Academic terms organization (Question 1 to 2): These questions are designed to analyze students' perception of the general semester workload

- Lectures organization (Question 3 to 8): They focused on students' perception of the course itself; such as the available materials, the clarity of assessment rules, the prerequisites and the course activities

- Teaching delivery (Question 9 to 13): This module includes the analysis of the lecturer performance; such as the lecture timeline, the availability, the clarity

- Facilities (Question 14 to 15): They evaluated the infrastructure and the software available

- Interest and satisfaction (Question 16 to 18): Students give general feedback on the course content independently from how it was delivered.

The aggregated data generates four indices that are used to evaluate the overall course: course index I1 (average of questions 1 to 18), lecturer index I2 (average of questions 9 to 13), course satisfaction S1 (\% positive answers 1 to 18), lecturer satisfaction S2 (\% positive answers 9 to 13$)$.

\section{Discussion}

The revised FSA started in October 2019 and lasted until the end of January 2020. 
Because the literature review highlighted as fundamental for a successful PBL implementation the tutoring support, before starting the course, the lecturer organized a meeting with the three assigned tutors. It explained the new approach and pointed out the critical role they play in the learning process. This meeting was the occasion for them to familiarize themselves with the team revision's sheet that, like a diary, keeps organized all the information regarding the tutoring sections of each team.

During the first lesson, the lecturer presented the new structure to the students, and they autonomously organize in 20 teams. The first tutoring section took place the second week of the course, and all groups attended, but only 13 were ready for a discussion with the tutors. Considering the overall tutoring sections, students highly attended them. Most of the teams were involved in their complete composition, and the members were actively speaking and interacting with the tutors. By looking at each team's revision sheets, it is clear that they started from a brainstorming stage with different ideas that evolved at different speeds. This personal learning path can be considered a positive thing because it allows students to regulate their learning and learn autonomously [25].

At the first presentation, 17 teams presented their idea. The quality of the presentation was well responding to the request. Each of the proposed bridges had a simple but different design. Considering the location, some of them chose a spot in their country of origin (mainly China, Colombia, Indonesia, Italy, Vietnam), others preferred a country external to the team, such as Sweden or Netherlands. Looking at the materials, some groups chose unusual ones like containers and bamboo while others employed more standard elements, like wood and steel. Four teams' ideas showed possible problems coming up in the following steps of the project. For this reason, after a quick talk with the teams, the lecturer explained to the tutors the possible structural issues to help the teams with the structure design and materials during the subsequent revision sessions.

Some teams decided not to show up at the following presentations because they struggled with structural issues, mainly trouble in calculations. In particular, at the second presentation, 10 teams succeeded in the speech, and at the third presentation, only 9 were positively addressing the lecturer's requests. In the meantime, the tutors tried to guide the teams through the difficulties they were facing. That explains why 17 teams delivered the reports and presented the final project at the end of the course. The lecturer commented on all the reports and returned them to prepare their final submission properly.

Regarding the issue related to the software Nòlian, the lecturer has provided a glossary reporting the English translation of the main commands and warning messages. The bridge design solution requires a 3D model evaluation with the related calculations using Nòlian. This exercise represents a real-world application and not a simple didactical training as it was in the old version of the course. That is, students become more familiar with Nòlian modelling.

Another difference has been observed in the assessment stage. Students approached the evaluation as soon as the course ended, which means they have been on track during the semester and felt familiar with the technical content. This on-time preparation translated into an increase in the average score in the winter exam's session. Table 3 reports 
Paper-Pedestrian Bridge Application in a Fundamentals of Structural Analysis Course Inside an...

the number of students that passed the exam and the average score in the different exam' sessions.

Table 3. Students distribution at the assessment and their average score

\begin{tabular}{|l|c|c|c|c|c|c|c|}
\hline & \multicolumn{3}{|c|}{ academic year 2018/19 } & \multicolumn{4}{c|}{ academic year 2019/20 } \\
\hline $\begin{array}{c}\text { Exam } \\
\text { session }\end{array}$ & $\begin{array}{c}\# \\
\text { students }\end{array}$ & $\begin{array}{c}\text { Test } \\
\text { results }\end{array}$ & $\begin{array}{c}\text { Average } \\
\text { score }\end{array}$ & $\begin{array}{c}\# \\
\text { Students }\end{array}$ & $\begin{array}{c}\text { Test } \\
\text { results }\end{array}$ & $\begin{array}{c}\text { Project } \\
\text { results }\end{array}$ & $\begin{array}{c}\text { Average } \\
\text { score }\end{array}$ \\
\hline Winter & $5(11 \%)$ & $21,4 / 30$ & $21,4 / 30$ & $41(66 \%)$ & $14,82 / 18$ & $10,29 / 12$ & $25,26 / 30$ \\
\hline $\begin{array}{l}\text { Summer and } \\
\text { Autumn }\end{array}$ & $33(73 \%)$ & $23,2 / 30$ & $23,2 / 30$ & $11(18 \%)$ & $14,18 / 18$ & $8,55 / 12$ & $22,78 / 30$ \\
\hline None & $7(16 \%)$ & & & $10(16 \%)$ & & & \\
\hline Total & 45 & & & 62 & & & \\
\hline
\end{tabular}

By looking at the anonymous course survey, there are no substantial differences in the overall evaluation between the two academic years under study. In the academic year 2019/2020, the indices were I1 3.19/4, I2 3.22/4, S1 83\%, S2 81\%. The only statistical difference exists on the question related to supplementary learning activities (question 8). With the introduction of PBL, the students' perception moved from 3.08 to $3.48 / 4$, increasing $20 \%$ in the satisfaction rate (from $76 \%$ to $96 \%$ ). Some students reported a different workload distributed during the entire semester and a better understanding of both the theoretical contents and the software application.

\section{Conclusion}

In general, the course participation has increased compared to the previous academic year in terms of presence during the lessons and interest in the subject. In particular, the interaction between the lecturer and the students increase. The students' requests are mainly addressing discussion about alternative computational solutions and specific material characteristics. This remark stimulated the lecturer to implement in theoretical lessons some active learning activities.

These results suggest a positive relationship between PBL and FSA in a non-technical program, such as an Architecture program. Architecture students are used to working in teams and are often asked to develop a project inside a course. In this way, the technical aspects, usually found to be the hardest ones, are better understood thanks to the tutoring activities and the peer-to-peer interactions. This process cannot be ensured to all the students because the PBL has a degree of freedom in the involvement and participation in the proposed activities (lessons, revisions and presentation). Indeed, 17 over 20 teams decided to constantly participate in the PBL approach with a personal and unique timing and flow in design creation. Moreover, the assessment's result strengthens the hypothesis of a better understanding of the technical structural analysis characteristics thanks to a concrete simple project design.

Considering the second research question, the possibility of locating the bridge all around the world and choosing materials that are more familiar for them is a positive aspect of this new methodology. Indeed, this freedom acts as leveraging on personal interests reinforcing and supporting the learning process. Another important aspect related to the heterogeneity of the class is the increase of peer-to-peer activities that have 
been registered since the beginning of the course. This informal and spontaneous interaction supports not only the computational side but includes in some cases also a theoretical discussion and study support activity.

Considering the positive results obtained during this first PBL implementation, starting from the academic year 2020/21, the FSA course is included in a design laboratory. Precisely, a design laboratory is a multidisciplinary course that involves different subjects' areas with a more complex project to be realized in teams.

\section{Acknowledgement}

For the development of this renewed version of the course, the interaction with DC Structures Studio has been crucial.

We also want to thank Giuseppe Brancaccio, Francesco Figura, and Emanuele Lavecchia, who play the critical role of tutors. Without their contribution, it would be hard to implement the PBL methodology properly.

\section{$7 \quad$ References}

[1] T. Andrade, "Project Based Learning Activities in Engineering Education," International Journal of Engineering Pedagogy (iJEP), vol. 3, pp. 27-32, 2013. https://doi.org/10.3991/ ijep.v3is 2.2438

[2] T. El-Maaddawy , H. El-Hassan and H. Al Jassmi , "Student Perceptions of the Use of Project-Based Learning in Civil Engineering Courses," in 2018 IEEE Global Engineering Education Conference (EDUCON), Santa Cruz de Tenerife, Canary Islands, Spain, 2018. https://doi.org/10.1109/educon.2018.8363235

[3] E. Justo, A. Delgado, M. Và Zquez-Boza and L. A. Branda, "Implementation of ProblemBased Learning in Structural Engineering: A Case Study," International Journal of Engineering Education, vol. 32, no. 6, pp. 2556-2568, 2016.

[4] T. Molyneaux, S. Setunge, R. Gravina and M. Xie , "An evaluation of the learning of structural engineering concepts during the first two years of a project-based engineering degree," European Journal of Engineering Education, vol. 32, no. 1, pp. 1-8, 2007. https://doi.org/10.1080/03043790601054793

[5] J. Morgan and L. Barroso, "Project Enhanced Learning in Structural Analysis," in Session $R 4 B$, San Juan, PR, July $23-28,2006$.

[6] S. Channdrasekaran and R. Al-Ameri, "Assessing Team Learning Practices in Project/Design Based Learning Approach," International Journal of Engineering Pedagogy (iJEP), vol. 6, no. 3, pp. 24-31, 2016. https://doi.org/10.3991/ijep.v6i3.5448

[7] M. J. Terrón-López, P.-J. Velasco-Quintana, M.-J. García-García, M.-C. Gaya-López and J.-J. Escibano-Otero, "Design and Implementation of a Comprehensive Educational Model: Project Based Engineering School (PBES)," International Journal of Engineering Pedagogy (iJEP), vol. 5, no. 3, pp. 53-60, 2015. https://doi.org/10.3991/ijep.v5i3.4673

[8] K. Mohd-Yusof, S. A. Helmi, M. Jamaludin and N. Harun, "Cooperative Problem-Based Learning (CPBL): A Practical PBL Model for a Typical Course," International Journal of Emerging Technologies in Learning (iJET), vol. 6, no. 3, pp. 12-20, 2011. https://doi. org/10.3991/ijet.v6i3.1696 
Paper-Pedestrian Bridge Application in a Fundamentals of Structural Analysis Course Inside an...

[9] I. Syamsuddin, "Problem Based Learning on Cloud Economics Analysis Using Open Source Simulation," International Journal of Online and Biomedical Engineering (iJOE), vol. 12, no. 6, pp. 4-9, 2016. https://doi.org/10.3991/ijoe.v12i06.5147

[10] A. Bridges, "A Critical Review of Problem Based Learning in Architectural Education," in Communincationn Space(s) in the 24th eCAADe, Volos, Greece, 2006.

[11] E. De Graaff and A. Kolmos, "Characteristics of Problem-Based Learning," International journal of Engineering Education, vol. 19, no. 5, pp. 657-662, 2003.

[12] M. G. Ballatore, F. Barpi and A. Tabacco, "Work-in-Progress: Pedestrian bridge application in a Fundamentals of Structural Analysis course inside an Architecture bachelor program," in 20 IEEE Global Engineering Education Conference (EDUCON), Porto, 2020. https://doi.org/10.1109/educon45650.2020.9125140

[13] J. A. Álvarez, J. Segundo, C. Álvarez, J. Arellano and A. A. Pérez, "Evaluation of the Use of Two Teaching Techniques in Engineering," International Journal of Engineering Pedagogy (iJEP), vol. 4, no. 3, pp. 4-10, 2014. https://doi.org/10.1109/educon45650. $\underline{2020.9125140}$

[14] Softing, "Nòlian L'analisi general pourpose con il FEM," [Online]. Available: http://www.softing.it/nolian.html. [Accessed 2510 2019].

[15] DC Structures Studio, "https://www.dcstructuresstudio.com/dcss-standard-footbridgedesign-2017/," NZ Standard Footbridge Design, 2017. [Online]. [Accessed 510 2019].

[16] Centre for Urban Design, "Bridge Aesthetics Design guideline to improve the appearance of bridges in NSW," 2019. [Online]. Available: https://www.rms.nsw.gov.au/documents/ projects/planning-principles/urban-design/bridge-aesthetics-guidelines.pdf.

[17] A. Charleson, Structure As Architecture A Source Book For Architects And Structural Engineers, Elsevier, 2005.

[18] Delft, "Brief Dutch Design Manual for Bicycle and Pedestrian Bridges," 2015. [Online]. Available: https://www.eiseverywhere.com/file_uploads/84d67431518b85c3fbfa30e607 3596c3_Brief_Dutch_Design_Manual_for_Bicycle_and_Pedestrian_Bridges_v1.3.pdf.

[19] A. Macdonald, Structure and Architecture, Elsevier, 2001.

[20] Decreto del Ministero dei Lavori Pubblici, "Norme tecniche per le costruzioni," 17012018. [Online]. Available: http://www.cslp.it/.

[21] European Committee for Standardization, "Eurocode 2: Design of concrete structures," CEN, Brussels, 2005.

[22] A Biographical Memoir by Ben R. Rich, Clarence Leonard (Kelly) Johnson 1910-1990, Washington D.C.: National Academies Press, 1995.

[23] A. Basson and T. von Backström, "Guide for Writing Technical Reports," Stellenbosch University, 2017.

[24] The Institution of Engineering and Technology, "A Guide to Technical Report Writing," 2015.

[25] M. Zarouk, E. Olivera, P. Peres and M. Khaldi, "The Impact of Flipped Project-Based Learning on Self-Regulation in Higher Education," International Journal Of Emerging Technologies In Learning, vol. 15, no. 17, pp. 127-147, 2020. https://doi.org/10.3991/ijet. v15i17.14135

[26] DC Structures Studio, "Laurent Swale Footbridge," [Online]. Available: https://www. dcstructuresstudio.com/laurent-swale-footbridge/. [Accessed 510 2019]. 


\section{Authors}

Maria Giulia Ballatore is a Research Fellow at the Department of Mathematical Sciences of the Politecnico di Torino, Italy. In the meantime, she is a PhD student in Engineering Education at the School of Electrical and Electronic Engineering, Technological University Dublin, Ireland. Her research interests lie in the fields of engineering education, development and standardization of learning technology, spatial abilities and gender issue. ORCID: 0000-0002-6216-8939

Prof. Fabrizio Barpi is an Associate professor of Structural Mechanics at the Department of Structural, Geotechnical and Building Engineering, Politecnico di Torino.He received the PhD in Structural Engineering at Politecnico di Torino in 1996 with a thesis on the numerical models for the study of cracking phenomena in dams. In 2014 was appointed by the Italian Minister as a member of the Advisory Commission of the Technical Standards for Dams. His research interests are continuum mechanics, computational mechanics, nonlinear finite element method, fracture mechanics, dam behaviour and snow avalanches dynamics. Recently, he started to work in the field related to education, in particular on Engineering Education. He is the author of several publications in international journals. Orcid: 0000-0001-8371-5690

Dan Crocker has over 15 years of experience designing bridges in Australasia, Europe, South America, and Asia. Dan is a Chartered Engineer (CEng) of the Institution of Civil Engineers (UK) and a Chartered Professional Engineer (CPEng) with the Institution of Professional Engineers NZ (IPENZ). Dan has designed over 50 bridges ranging from concept all the way through to construction and including the majority of materials and structural forms, including prestressed concrete beams, post-tensioned concrete beams, long-span steel composite beams, and glutamylated timber beams. Dan has also led the design of sophisticated bridges forms such as cable-stayed bridges, suspension bridges, and tied arch bridges. Dan is well respected and has previously held the role of Chairman for the Auckland Structural Group (ASG) with its plus 1,000strong membership of structural engineers. Dan is passionate about designing and constructing bridges and working with clients and constructors to create great infrastructures that communities can be proud of.

Prof. Anita Tabacco is a full professor since 2002 at the Department of Mathematical Sciences of the Politecnico di Torino. She received a PhD in Mathematics in 1986 at Washington University in St. Louis (MO), USA. Her mathematical research activities are related to real and complex analysis, functional analysis, harmonic analysis with a particular interest in interpolation theory, wavelets and applications to PDE and integral equations. Moreover, she is working in the field of Engineering Education. Her research activities include organizing conferences, workshops and graduate schools the participation in numerous prestigious research projects, both national and international. She is the author of numerous papers and has given many invited seminars and lectures in Italy and abroad. ORCID: 0000-0001-5731-4885

Article submitted 2020-11-30. Resubmitted 2021-07-23. Final acceptance 2021-07-26. Final version published as submitted by the authors. 